IZA DP No. 4942

Does International Outsourcing Really Lower Workers' Income?

Erkki Koskela

J an König

May 2010 


\title{
Does International Outsourcing Really Lower Workers' Income?
}

\author{
Erkki Koskela \\ University of Helsinki \\ and IZA
}

Jan König

Freie Universität Berlin

\author{
Discussion Paper No. 4942 \\ May 2010
}

\author{
IZA \\ P.O. Box 7240 \\ 53072 Bonn \\ Germany \\ Phone: $+49-228-3894-0$ \\ Fax: +49-228-3894-180 \\ E-mail: iza@iza.org
}

Any opinions expressed here are those of the author(s) and not those of IZA. Research published in this series may include views on policy, but the institute itself takes no institutional policy positions.

The Institute for the Study of Labor (IZA) in Bonn is a local and virtual international research center and a place of communication between science, politics and business. IZA is an independent nonprofit organization supported by Deutsche Post Foundation. The center is associated with the University of Bonn and offers a stimulating research environment through its international network, workshops and conferences, data service, project support, research visits and doctoral program. IZA engages in (i) original and internationally competitive research in all fields of labor economics, (ii) development of policy concepts, and (iii) dissemination of research results and concepts to the interested public.

IZA Discussion Papers often represent preliminary work and are circulated to encourage discussion. Citation of such a paper should account for its provisional character. A revised version may be available directly from the author. 


\section{ABSTRACT}

\section{Does International Outsourcing Really Lower Workers' Income?}

We analyze the impact of international outsourcing on income, if the domestic labor market is imperfect. We distinguish in our analysis between the case where the parties negotiate over the wage only and where they negotiate over both wage and profit share. We find that in the first case outsourcing will reduce (increase) workers' income, if the labor union's bargaining power is sufficiently high (low) and outsourcing will increase workers' income in the second case. For the amount of optimal international outsourcing, we find that it is in a pure wage bargaining system positively (negatively) affected by a sufficiently high (low) labor union's bargaining power, while in a wage and profit share bargaining system, a higher union's bargaining power decreases the optimal amount of outsourcing.

JEL Classification: E23, E24, J23, J33, J82

Keywords: strategic outsourcing, profit sharing, labor market imperfection

Corresponding author:

Erkki Koskela

Department of Economics

University of Helsinki

P.O. Box 17 (Arkadiankatu 17)

$\mathrm{FI}-00014$

Finland

E-mail: erkki.koskela@helsinki.fi

\footnotetext{
* Koskela thanks the Academy of Finland (grant No. 1217622) for financial support and Freie Universität Berlin for good hospitality. König thanks University of Helsinki for good hospitality.
} 


\section{Introduction}

In the last years, because of the growing globalization, international outsourcing, which is understood as the buying of production parts from an independent foreign supplier, has become an important part in firms' management to reorganize the production process. ${ }^{1}$ Attended with this observation, many people fear the wide consequences for the domestic labor market, especially for ordinary workers. Due to the possibility of substitution, such consequences may be the loss of employment or a reduction of the wage and, therefore, a lower income. ${ }^{2}$ In this situation, the labor market structure and the existence of a trade union, which can use its power to avoid a dramatic wage decrease and/or bargain with the firm over employment guarantees, play an important role.

This paper presents a theoretical framework to analyze the effects of committed international outsourcing on workers' income, if workers are represented by a labor union. ${ }^{3}$ Thus, we assume an imperfect domestic labor market, i.e. a firm and a labor union negotiate over workers' remuneration, while we distinguish between two kinds of negotiation. In the first part, we follow the classical bargaining approach, where only the wage is determined, while in the second part we assume an alternative approach where the firm and the labor union bargain over wage and profit sharing.

Due to the actuality and importance of this topic, there is a growing amount of literature relating to the effect of outsourcing or globalization on wages and employment. From a theoretical point of view, Danthine and Hunt (1994) show that due to globalization product market competition intensifies and, as a consequence, lower profits occur, which leads to a wage moderating effect in unionized sectors. A similar finding is presented by Glass and Saggi (2001). Opposed to that, Naylor $(1998,1999)$ find that domestic unionized workers may profit from globalization in

Empirical studies like Hummels et al. (1998, 2001) or Yeats (2001) show the increase of imported intermediate goods over the last 30 years.

2 For an overview concerning the debate on employment effects due to outsourcing, see Freeman (1995) and Bhagwati et al. (2004).

3 In the committed case, outsourcing takes place before wage bargaining. Thus the external procurement is seen as a long-term contract that fixes the amount of outsourcing. See e.g. Perry (1997) for an overview about the relationship between outsourcing and wage bargaining. 
terms of higher wages and employment, since the total production expands if new markets can be served by the firms. Lommerud et al. (2009) show, that higher market integration favours outsourcing to low cost countries and increases the wage due to a less elastic labor demand. The reason is that the used inputs are complements and thus for a given amount of outsourcing, the loss of the labor union of a higher wage will decrease. However, there are also studies, such as Skaksen and Sorensen (2001) or Koskela and Stenbacka (2009), which show that the wage effect of foreign direct investments or outsourcing is a priori ambiguous. In Skaksen and Sorensen (2001), the degree of substitution between the activities in the home country and abroad is decisive for the domestic wage effect. If the activities are good substitutes, a lower domestic wage results and domestic employment loses, while a higher base wage results from complementary activities and thus, employment gains. In Koskela and Stenbacka (2009), the wage effect of outsourcing depends on the labor unions relative bargaining power, where it lowers (increases) the wage if the labor union's bargaining power is sufficiently high (low).

Empirical studies also analyze the wage effect of international outsourcing. In an early study, Feentsra and Hanson (1999) show the wage reducing effect for low-skilled workers in the United States over the period 1979-1990. Senses (2010), also using U.S. data, provides empirical evidence of an increasing wage elasticity and thus for a wage moderating effect of outsourcing. ${ }^{4}$ Focusing on German data, Geishecker and Görg (2008) identify winners and losers from international outsourcing depending on the skills of the workers. Although the German labor market is characterized by relatively rigid wages, there may be a wage moderation effect of outsourcing, if it improves the outside option of the firm. The authors find that this happens to low-skilled workers, who receive a lower wage with increasing outsourcing. In contrast, the high-skilled wage increases. This is reasonable with a higher relative high-skilled demand if the low-skilled intensive parts are outsourced.

As seen above, the theoretical studies focus on pure wage effects of international outsourcing, by assuming that only the wage is determined by the bargaining between the firm and the labor union. However, not only the wage, but additional components as bonus payments or profit sharing can be the result of such

Similar findings are shown in earlier studies by Slaughter (2001) and Hasan et al. (2007). 
bargaining. ${ }^{5}$ The idea behind the incorporation of profit sharing in a compensation scheme is to stimulate the motivation and identification with the firm and thus to increase productivity. ${ }^{6}$ Using this assumption, we extend the above-mentioned literature by implementing profit sharing as a part of the compensation scheme. ${ }^{7}$ The distinction between the case where the union and firm negotiate over wages only, and the case where both, the wage and a profit share are negotiated, allows us to discern between a wage and income effect. Thus, our central research question is: Is there a justified fear of income loss for unionized workers?

In our analysis, we find that in the case where the firm and the labor union bargain over the base wage only, outsourcing will reduce (increase) workers' income, if the labor union's bargaining power is sufficiently high (low). In contrast, if the labor union and firm bargain simultaneously over wage and profit share, outsourcing will increase workers' income, if the marginal costs of outsourcing are lower than the domestic outside option.

Knowing the effect of income respectively wage effects, based on comparative statics we can show in which way the degree of labor market imperfection, i.e. the union's bargaining power, affects the domestic outsourcing demand under the different remuneration schemes. Here, we find that the outsourcing demand under a pure wage bargaining system will become higher (lower) if the labor union's bargaining power is sufficiently high (low), while under a simultaneous wage and profit share bargaining system the amount of outsourcing decreases with stronger labor union.

We proceed as follows. Section II presents the time sequences of decisions in terms of outsourcing, employment, wage formation and profit sharing. Section III investigates solving the model in terms of domestic labor demand, and bargaining

5 Empirical studies as Pendleton et al. (2001) show that profit sharing is an often used compensation scheme in many OECD countries. For further evidence regarding the incidence of profit sharing, see also Estrin et al. (1997) and Conyon and Freeman (2004).

6 However, empirical studies show that the productivity effects are ambiguous. For an increasing effect on productivity, see Cable and Fitzroy (1980), while Jones and Pliskin (1991) and Kruse (1993) demonstrate negative productivity effects of profit sharing.

7 There are some studies, who analyze the implementation of profit sharing in collective bargaining, e.g. Holmlund (1990) and Jerger and Michaelis (1999). Concerning the efficiency property, Pohjola (1987) and Anderson and Devereux (1989) show that also without an employment determination the outcome of a collective bargaining is efficient by introducing bargaining over wages and profit share. However, all studies abstract from outsourcing. 
process in terms of wage formation and both wage formation and profit sharing and also strategic outsourcing. Finally, we present conclusions in section IV.

\section{Basic Framework}

We assume that in our economy there is a representative firm which produces the final good using two activities. The relationship of these activities can be represented by the Cobb-Douglas production function

$$
F=X^{\alpha} \cdot Y^{\beta} \text { with } 0<\alpha+\beta<1
$$

where $X$ and $Y$ characterize the two input goods. We assume that the $X$-activity must take place in-house, whereas the $Y$-activity can be produced in-house or be outsourced. For simplicity, we assume a linear technology in every input production, where for one unit of the input good, one unit of labor, respectively outsourced input is needed. Therefore, we specify the production function for the input goods as

$$
\begin{aligned}
& X=L^{X} \\
& Y=L^{Y}+M,
\end{aligned}
$$

where $L^{X}$ and $L^{Y}$ present the labor demand in the specific activity and $M$ the amount of outsourcing.

We further assume that labor in both activities is homogenous and that the overall workforce $L=L^{X}+L^{Y}$ will be represented by a labor union and thus. This assumption assures that no wage discrimination between the activities can be realized by the firm.

The structure of actions can be interpreted as sequential decisions on three stages. On the first stage, the representative firm commits to the amount of outsourcing before the bargaining process and domestic labor demand. After the firm has decided about outsourcing, the firm and the labor union bargain over i) the 
wage level or ii) the base wage and profit sharing. Since the firm has the right-tomanage, it determines the employment according its labor demand after knowing the bargaining results. We summarize these timing decisions in Figure 1.

Figure 1: Time sequences

\begin{tabular}{lll} 
Stage 1 & Stage 2 & Stage 3 \\
\hline outsourcing $M$ & $\begin{array}{l}\text { bargaining process } \\
\text { (wage } w \text { or wage } w \\
\text { and profit sharing } \tau \text { ) }\end{array}$ & labor demand $L$ \\
&
\end{tabular}

The decisions at each stage are analyzed by using backward induction.

\section{Solving the Model}

In the next parts, we solve the presented timing structure. We first focus on the third stage by deriving the labor demand in both activities for given outsourcing. After that, we model the bargaining process by distinguishing the mentioned two alternative approaches. While in the first approach, the firm and the labor union bargain over the wage level only, in the second approach, both parties negotiate about wage and profit share. Finally, at the first stage we solve for the optimal strategic outsourcing.

\section{III.1. $3^{\text {rd }}$ stage: Domestic Labor Demand}

The firm decides on domestic labor to maximize the profit function

$$
\underbrace{\operatorname{Max}}_{L_{X} ; L_{Y}} \pi=\left(L^{X}\right)^{\alpha} \cdot\left(L^{Y}+M\right)^{\beta}-w\left(L^{X}+L^{Y}\right)-f(M),
$$

taking outsourcing, $M$, as given. For the cost of outsourcing, $f(M)$, we assume that there are some other costs associated with outsourcing, such as the price of the intermediate goods. Such costs could be costs for transport, which are exponentially 
increasing with higher outsourcing. To allow for an exponential cost increase, we model a quadratic cost function, $f(M)=\frac{1}{2} c M^{2}, c>0$, with $f^{\prime}(M)>0$ and $f^{\prime \prime}(M)>0$. As one can see from (2), the firm maximizes profits with respect to $L^{X}$ and $L^{Y}$. This leads to the standard result, that employment is set where marginal productivity equals the wage rate. From these first-order conditions we get the labor demand for given outsourcing ${ }^{8}$

$$
\begin{aligned}
& L^{X}=w^{-\frac{1}{1-\alpha-\beta}} \cdot \alpha^{\frac{1-\beta}{1-\alpha-\beta}} \cdot \beta^{\frac{\beta}{1-\alpha-\beta}}, \\
& L^{Y}=w^{-\frac{1}{1-\alpha-\beta}} \cdot \alpha^{\frac{\alpha}{1-\alpha-\beta}} \cdot \beta^{\frac{1-\alpha}{1-\alpha-\beta}}-M .
\end{aligned}
$$

Thus, the overall domestic labor demand is

$$
L=L^{X}+L^{Y}=(\alpha+\beta) \cdot w^{-\frac{1}{1-\alpha-\beta}} \cdot \alpha^{\frac{\alpha}{1-\alpha-\beta}} \cdot \beta^{\frac{\beta}{1-\alpha-\beta}}-M .
$$

As one can see from equation (4), domestic labor demand is a negative function of both wage and the amount of outsourcing, where the substitutability of low-skilled labor and international outsourcing is consistent with empirical evidence, e.g. presented by Görg and Hanley (2005).

Since we focus on wage bargaining, the labor union keeps in mind the reaction of labor demand concerning wage changes, while the degree of labor demand reaction is presented by the wage elasticity of labor demand. In the presence of outsourcing the wage elasticity of labor, $\eta=-\frac{\partial L}{\partial w} \frac{w}{L}$, can be written as

$$
\eta=\frac{1}{1-\alpha-\beta}\left(1+\frac{M}{L}\right)>1
$$
$(1-\tau) \cdot \pi$, we yield the same labor demand reactions, since it works as a profit tax. Since this kind of tax is neutral, the domestic labor demand is independent of bargained profit sharing. 
Notice that the wage elasticity (5) depends on wage and outsourcing. For the effects of these variables, we find $\eta_{w}=\frac{1}{1-\alpha-\beta} \cdot \frac{\eta}{w} \cdot \frac{M}{L}>0$ and $\eta_{M}=\frac{\eta}{L}>0$. Therefore, with higher domestic wage and higher outsourcing, labor demand becomes more elastic. In the absence of outsourcing, the wage elasticity $\left.\eta\right|_{M=0}=\frac{1}{1-\alpha-\beta}$ is constant and smaller than in the presence of outsourcing. ${ }^{9}$

\section{III.2. $2^{\text {nd }}$ stage: Bargaining Process}

At this stage, the firm and a labor union bargain over i) the wage level or ii) the wage and profit sharing. We distinguish between these scenarios since both are possible in observed bargaining rounds. ${ }^{10}$

The outcome of the bargaining process is assumed to be determined by the Nash-Bargaining-Solution, where the Nash-Product is defined as

$$
\Omega=\left(U-U_{0}\right)^{\gamma} \cdot\left(\hat{\pi}-\pi_{0}\right)^{1-\gamma}
$$

In the above notation, $U_{0}$ and $\pi_{0}$ are the disagreement payoffs for the union respectively the firm. In the case of a disagreement, there is no production, implying that every union member get the outside option. Formally, this is expressed as $U_{0}=N \cdot b$, where $b$ captures the exogenous minimum income for labor union members $N$. On the other side, due to non-production, the firm loses its investment in outsourcing, $\pi_{0}=-f(M)$, which means that the firm has an incentive for an agreement.

These findings are in line with empirical evidence as shown by Slaughter (2001), Hasan et al. (2007) and Senses (2010).

10 While in most European countries as Austria, Germany, Sweden or Finland the wage is the central determinant in a bargaining between the union and the firm, in France there exists a obligatory profit share system for firms with more than 50 workers, while in the bargaining round, the firm and the labor union determine the details such as the calculation formula or the duration. See also Pendleton et al. (2001). 


\section{III.2.1 Parties Bargaining Over Wages Only}

Assuming that only the wage will be determined, we can express the bargaining problem as

$$
\max _{w} \Omega=\left(U-U_{0}\right)^{\gamma} \cdot\left(\hat{\pi}-\pi_{0}\right)^{1-\gamma} .
$$

To describe the preferences of the labor union we model an utilitarian union utility $U=u(w) \cdot L+u(b) \cdot(N-L)$ in case of agreement, where the individual utility $u$ is linear in income, i.e $u(w)=w$ and $u(b)=b$. Combining this with the unions outside option $U_{0}$, we can express the union rent as $\bar{U}=U-U_{0}=(w-b) L$.

The bargaining rent of the firm, $\bar{\pi}=\pi-\pi_{0}$, can also be expressed explicitly. Since the profit in case of an agreement is $\pi=F-w L-f(M)$ and the disagreement profit is $\pi_{0}=-f(M)$, we obtain as the rent $\bar{\pi}=F-w L$.

Maximizing the Nash-Product (see also chapter 7 in Cahuc and Zylberberg, 2004), the first-order condition can be written as $\Omega_{w}=0=\gamma \frac{\bar{U}_{w}}{\bar{U}}+(1-\gamma) \frac{\bar{\pi}_{w}}{\bar{\pi}} \cdot{ }^{11}$ Using our earlier results, we have

$$
\frac{\bar{U}_{w}}{\bar{U}}=\frac{L_{w}}{L}+\frac{1}{w-b}=\frac{1}{w} \cdot\left(-\eta+\frac{w}{w-b}\right),
$$

and

$$
\frac{\bar{\pi}_{w}}{\bar{\pi}}=-\frac{1}{w} \frac{\alpha+\beta}{(1-\alpha-\beta)+M / L} .
$$

Using these expressions as well as the wage elasticity of labor, the firstorder condition of the Nash-product can be solved to

$$
w=A(w, M, \gamma) \cdot b
$$

For notational convenience, we use the subscript as a characterization for the first derivative, i.e. $\Omega_{w}=\partial \Omega / \partial w$. 
which corresponds to the standard result that the wage consists of the outside option and a mark-up bigger than one. As one can see, in our framework, the mark-up $A=\frac{\gamma \cdot \eta[\eta(1-\alpha-\beta)-(\alpha+\beta)]+(1-\gamma)(\alpha+\beta)}{(\eta-1) \gamma \cdot[\eta(1-\alpha-\beta)-(\alpha+\beta)]+(1-\gamma)(\alpha+\beta)}>1$ depends on the relative bargaining power of the labor union $\gamma$, outsourcing $M$ and wage $w$. Therefore, equation (7) is an implicit formulation.

Knowing the bargained wage, we can distinguish the extreme cases of monopoly labor union, which sets the wage independent from the firm, and the absence of a labor union, where the firm sets the wage independently. The approach of a monopoly labor union is characterized by $\gamma=1$, where the wage is $\left.w\right|_{\gamma=1}=\frac{\eta}{(\eta-1)} \cdot b$, while in the absence of bargaining power of the labor union $\left.w\right|_{\gamma=0}=b \cdot{ }^{12}$

To answer our research question and characterize the wage effect of outsourcing, we now turn to a detailed analysis. Implicit differentiation of (7) with respect to outsourcing gives $\frac{d w}{d M}=\frac{A_{M} b}{1-A_{w} b}$ and by substituting $b=w / A$, we can characterize the impact of international outsourcing on wage formation as

$$
\frac{d w}{d M}=\frac{\frac{A_{M} w}{A}}{1-\frac{A_{w} w}{A}},
$$

where $1-\frac{A_{w} w}{A}>0 .{ }^{13}$

The outsourcing effect on the mark-up, $\frac{A_{M} w}{A}$, is a priori ambiguous and depends on the relationship between the relative bargaining power of the labor

12 Since $\eta>1$, it is easy to see that the relative bargaining power of the labor union will have a positive effect on the mark-up in the general case $0<\gamma<1$. This means that $A_{\gamma}>0$.

13 For the detailed derivations see Appendix A. 
union, $\gamma$, and the outsourcing and labor ratio, $M / L$. For the impact of outsourcing on the mark-up, we find

$$
A_{M}\left\{\begin{array}{l}
< \\
>>
\end{array}\right\} \quad \text { if } \quad \gamma\left\{\begin{array}{l}
> \\
= \\
<
\end{array}\right\} \frac{(1-\alpha-\beta)(\alpha+\beta)}{(1-\alpha-\beta)(\alpha+\beta)+[(1-\alpha-\beta)+M / L]^{2}} .
$$

Thus, for a sufficiently strong (weak) labor market imperfection characterized by the relative bargaining power of the labor union, outsourcing has a wage moderating (wage increasing) effect.

As above, we can also identify the wage effect of outsourcing in the extreme cases. Since with unilateral wage setting by the firm, the wage will be at the lowest possible level, which is the exogenous outside alternative income, outsourcing has no wage effect, i.e. $\left.\frac{d w}{d M}\right|_{\gamma=0}=0$. In contrast, in the case of monopoly labor union we find that $\left.A_{M}\right|_{\gamma=1}<0$, which yields $\left.\frac{d w}{d M}\right|_{\gamma=1}<0$.

Concerning the more general case where both parties are endowed with a positive bargaining power, i.e. $0<\gamma<1$, we can summarize as

Proposition 1: If the firm and the labor union bargain over the base wage only, outsourcing will reduce (increase) workers' income, if the labor union's bargaining power is sufficiently high (low).

A similar result is obtained by Koskela and Stenbacka (2009) in the model where profit sharing has not been analyzed.

As the reason for this ambiguous the effect of outsourcing on wage formation, we can identify two opposite mechanisms. First, with higher outsourcing the wage elasticity of labor demand (5) becomes more elastic. Due to a more elastic labor demand, a higher wage increases the union's utility loss of less employment. This mechanism on the union's utility induces discipline and makes the labor union less aggressive, which means a lower wage mark-up. Second, as outsourcing and 
labor are substitutes, with higher outsourcing the firm's profit is less dependent of labor costs. Thus, outsourcing moderates the profit-reducing effect $\pi_{w} / \pi$ of a wage increase, which promotes a higher wage mark-up. As equation (9) reflects, the overall effect on the negotiated wage of increased outsourcing is a trade-off between these two forces, while the first effect dominates when the labor market imperfection $\gamma$ is sufficiently strong.

\section{III.2.2 Simultaneous Bargaining Over Wage and Profit Share}

As mentioned in the introduction, there are several studies concerning the simultaneous negotiation about profit sharing and wages. However, these studies abstract from strategic outsourcing.

Before we formally analyze this bargaining process, we have to modify our objective function of the labor union and the firm. Since we assume that the union utility depends on income, we now have to write the utility in case of an agreement as $U=w L+\tau \pi$, where $\tau$ characterizes the share of profit which is distributed to the workers. Of course, the profit of the firm's owner will change, too. In the case of an agreement he now gets $(1-\tau) \cdot \pi$. Since the value of disagreements are the same as in section III.2, i.e. $U_{0}=N \cdot b$ and $\pi_{0}=-f(M)$, the rents are now represented by $\bar{U}=U-U_{0}=(w-b) L+\tau \pi$ and $\bar{\pi}=(1-\tau) \pi+f(M)$. In this setting, the Nash-Product has to be maximized concerning wage and profit share, i.e. $\max _{w, \tau} \Omega=\bar{U}^{\gamma} \cdot \bar{\pi}^{1-\gamma}$. As first-order conditions, we get

$$
\Omega_{w}=0=\gamma \frac{\bar{U}_{w}}{\bar{U}}+(1-\gamma) \frac{\bar{\pi}_{w}}{\bar{\pi}},
$$

and

$$
\Omega_{\tau}=0=\gamma \frac{\bar{U}_{\tau}}{\bar{U}}+(1-\gamma) \frac{\bar{\pi}_{\tau}}{\bar{\pi}} .
$$


Using $\bar{U}_{\tau}=\pi$ and $\bar{\pi}_{\tau}=-\pi$ from (10b), we have $\frac{\gamma}{\bar{U}}=\frac{1-\gamma}{\bar{\pi}}$. Putting this expression in (10a), we get $0=\bar{U}_{w}+\bar{\pi}_{w}$, where $\bar{U}_{w}=L_{w}(w-b)+(1-\tau) L$ and $\bar{\pi}_{w}=-(1-\tau) L$. Using these results, we obtain a negotiated base wage, in the presence of simultaneous negotiations with wage and profit sharing, of

$$
w=b,
$$

so that the negotiated wage in the presence of negotiated profit sharing is equal to the exogenous outside option for labor union members. ${ }^{14}$

Comparing the negotiated wages (7) and (11) implies that the wage in the simultaneous wage and profit sharing bargaining is smaller than (equal to) the wage in the case without profit sharing negotiation, if there is a positive (zero) relative bargaining power of the labor union. The intuition for this finding is relatively simple, since the parties bargain over the distribution of the earned rent. If there is no labor union, the whole rent will be earned by the firm. Since the rent is influenced by the employment, and the highest rent is realized with the highest employment, the firm reduces the paid wage to the lowest possible level, which is the outside option $b$. The same mechanism leads to the derived result (11) in the presence of simultaneous bargaining of profit sharing and wage. Both parties maximize the rent and fix the wage on the lowest level, while the distribution of the rent between the firm and the labor union will be determined by the negotiated profit share level.

Implementing (11) in $\frac{\gamma}{\bar{U}}=\frac{1-\gamma}{\bar{\pi}}$ and using the labor demand (3a) and (3b), we obtain the bargained profit share

$$
\tau=\gamma \cdot \frac{b^{-\frac{\alpha+\beta}{1-\alpha-\beta}} \cdot \alpha^{\frac{\alpha}{1-\alpha-\beta}} \cdot \beta^{\frac{\beta}{1-\alpha-\beta}}(1-\alpha-\beta)+b M}{b^{-\frac{\alpha+\beta}{1-\alpha-\beta}} \cdot \alpha^{\frac{\alpha}{1-\alpha-\beta}} \cdot \beta^{\frac{\beta}{1-\alpha-\beta}}(1-\alpha-\beta)+b M-f(M)} .
$$

\footnotetext{
14 This corresponds to the well known results of Weitzman (1987).
} 
From (12) we see that in the absence of outsourcing the profit share corresponds to the relative bargaining power of the labor union, i.e. $\left.\tau\right|_{M=0}=\gamma^{15}$, while in the presence of outsourcing, the bargaining profit share is smaller than the relative bargaining power of the labor union, i.e. $\left.\tau\right|_{M>0}<\gamma$.

As mentioned above, the profit share determines how the created rent distributed between the two parties. One would expect that the distribution of the rent is driven by the relative bargaining power and the share of the rent for every party equals its relative bargaining power. However, as shown in equation (12), this does not hold in our framework under the assumption of strategic outsourcing. The economic intuition for this result is the following: Since the amount of outsourcing is determined before the bargaining takes place, the firm has an incentive to reach an agreement and to avoid the negative profit, being the costs associated with the outsourcing commitment. Thus the firm faces a weaker position than in the case of an outside option with zero profits, where only the relative bargaining power is decisive for the distribution. Therefore, the firm receives a lower share of the rent than its relative bargaining power predicts.

Since in the former analysis the wage equals to the income, the wage effect of outsourcing and the income effect of outsourcing are the same. However, in the case of a simultaneous bargaining over wage and profit share we have two income components. Thus, in contrast to the former analysis, these are different effects and we can now discern between them.

As equation (11) shows, the wage is the constant exogenous outside option and not affected by the outsourcing demand so that there will be no wage effect of outsourcing. However, strategic outsourcing affects the profit in the case of no agreement and thus, it influences the incentive of the firm to find an agreement, which means that workers' profit income is affect via the negotiated profit share. To determine this effect of outsourcing, we have to show the effect of outsourcing on the negotiation profit share. Here we find that (see Appendix B)

15 For this standard result see also Holmlund (1990). 


$$
\frac{\partial \tau}{\partial M}=\gamma \frac{c M\left[V+\frac{1}{2} b M\right]}{(V+b M-f(M))^{2}}>0
$$

where $V=b^{-\frac{\alpha+\beta}{1-\alpha-\beta}} \alpha^{\frac{\alpha}{1-\alpha-\beta}} \beta^{\frac{\beta}{1-\alpha-\beta}}(1-\alpha-\beta)>0$, so that the bargained profit share depends positively on outsourcing.

However, our research question focuses on the overall income effect of outsourcing, which is corresponds to the impact on workers' profit income. Under this kind of compensation scheme, the income of an employed individual is $\omega=b+\tau \cdot \frac{\pi^{*}}{L}$, where the income effect of outsourcing can be formalized by

$$
\frac{\partial \omega}{\partial M}=\frac{\partial \tau}{\partial M} \cdot \frac{\pi^{*}}{L}+\frac{\tau}{L^{2}}\left[\frac{\partial \pi^{*}}{\partial M} \cdot L-\frac{\partial L}{\partial M} \cdot \pi\right]>0 .
$$

Using the former results (4) and (13), we have $\frac{\partial \tau}{\partial M}>0$ and $\frac{\partial L}{\partial M}<0$. To determine the outsourcing effect on profit, we need the indirect profit function $\pi^{*}$. Using the derived result, we find that $\pi^{*}=(1-\alpha-\beta) \cdot \alpha^{\frac{\alpha}{1-\alpha-\beta}} \cdot \beta^{\frac{\beta}{1-\alpha-\beta}} \cdot b^{-\frac{\alpha+\beta}{1-\alpha-\beta}}+b \cdot M-f(M)$ and thus $\frac{\partial \pi^{*}}{\partial M}=b-\frac{\partial f(M)}{\partial M}$. As this formulation shows, under the assumption that the marginal cost of outsourcing, $\frac{\partial f(M)}{\partial M}$, are lower than the domestic marginal cost of labor, $b$, we have $\frac{\partial \pi^{*}}{\partial M}>0$ and therefore an unambiguous increasing income effect of outsourcing.

We can summarize our findings as

Proposition 2: If the labor union and the firm bargain simultaneously over wage and profit share, outsourcing will increase workers income, 
if the marginal costs of outsourcing are lower than the domestic outside option.

As one can see from (14), outsourcing affects the income in two ways. The first part shows the share-increasing effect, since every worker gets a higher share of the per capita profit. This effect results from the fact that higher outsourcing increases the loss of the firm if there is no agreement in the bargaining, which make the firm less aggressive and increases the negotiated profit share. The second mechanism is shown by the expression in brackets. On the one side, higher outsourcing will increase the profit. This is true since in the $Y$-activity, there will be an substitution of domestic labor by higher outsourcing, which leads to a higher profit, if the marginal costs of outsourcing are lower than the domestic marginal costs of labor. On the other side, due to the decreased employment the per capita profit increases. Due to these effects, an employed worker will benefit from higher outsourcing since the profit share, the overall and the per capita profit increase.

\section{III.3 Optimal Strategic Outsourcing}

So far, we have restricted ourselves to a short-run analysis, where the amount of outsourcing is given respectively constant, while the firm has committed itself. We now relax this point of view by exploring the initial stage of the outsourcing decision and thereby focusing on a long-run perspective, where the firm determines its investments into outsourced production. We can thus characterize in which way the equilibrium production mode is affected by the labor market characteristics concerning the relative bargaining power under the different bargaining structures.

\section{III.3.1 Optimal Outsourcing if Parties Bargain over Wages Only}

According to the timing structure presented in Section II, the representative firm has been assumed to commit to outsourcing to maximize profit (2) subject to 
domestic labor demand (4) and wage formation (7). As we have showen above, the indirect profit function is $\pi^{*}=(1-\alpha-\beta) \cdot \alpha^{\frac{\alpha}{1-\alpha-\beta}} \cdot \beta^{\frac{\beta}{1-\alpha-\beta}} \cdot w^{-\frac{\alpha+\beta}{1-\alpha-\beta}}+w \cdot M-f(M)$. Thus the firm's optimizing problem can be characterized by

$$
\max _{M} \pi^{*} \text { s.t. } w=A(w, M, \gamma) \cdot b \text { and } f(M)=\frac{1}{2} c M^{2}
$$

Differentiating the indirect profit function, yields as the first-order condition

$$
\frac{\partial \pi^{*}}{\partial M}=w-c M-\frac{d w}{d M} \cdot L^{Y}=0
$$

As equation (16) points out, the level of outsourcing depends on the employment used in activity $Y$ and on the labor market imperfection, which determines the wage effect (see equation (9)). As one can see from (16), under $L^{Y}>0$ and $d w / d M<0$ it follows that $c M>w$. Therefore, the amount of outsourcing lies above the outsourcing level where domestic and foreign marginal costs are equal. Since outsourcing moderates the wage only in the presence of a sufficiently high union bargaining power, we can conclude that under $L^{Y}>0$ strategic outsourcing is an increasing function of the labor market imperfection. Therefore, in the presence of a strong labor union, the firm reaps an additional benefit with higher outsourcing, by inducing a wage moderating effect. ${ }^{16}$

We can summarize our finding as

Proposition 3: If parties bargain over wages, strategic outsourcing will become higher (lower), if the labor union's bargaining power is sufficiently high (low).

This result can be explained as follows. On the one hand, higher outsourcing increases the total production costs, but on the other hand, it leads to a wage

For a graphical argumentation see Koskela and Schöb (2009). 
moderation if the labor union is sufficiently strong. Thus, outsourcing becomes a strategic instrument for the firm as it reduces the wage bill. As equation (16) characterizes, the optimal amount of outsourcing is given, where both effects are equalized. However, if there is no employment in activity $Y\left(L^{Y}=0\right)$ or no wage moderating effect, $d w / d M=0$, we get the usual result, where the marginal costs have to be the same.

The effect of unionization on the domestic wage level is also presented in Lommerud et al. (2009). In contrast to our analysis, they find an outsourcingdecreasing impact of higher labor union's bargaining power. This results from the fact, that higher outsourcing decreases the firm's marginal costs and thus the labor demand elasticity becomes less elastic, which leads to higher wages, which follows from the assumption of complementary inputs in the production technology. As in our analysis, higher outsourcing decreases domestic labor, but due to the complementarity for the remaining domestic inputs with the outsourced inputs, a stronger union will use its power to increase the wage and decrease the profit. Therefore the firm's incentive for more outsourcing decreases with higher union's bargaining power. In our model, we have a different assumption concerning the production technology. As one can see from (1), we model the remaining inputs and outsourcing as substitutes, which lead to a wage decrease of higher outsourcing in the presence of a sufficiently strong labor union. Thus, the major difference between the two analyses results from the different assumption of product technology, which lead to different effects on the domestic labor demand elasticity and therefore on the bargaining outcome.

\section{III.3.2 Optimal Outsourcing if Parties Bargain over Wage and Profit Share}

Since in this scenario, the wage is set to the constant outside option, the indirect profit becomes 
$\pi^{*}=(1-\alpha-\beta) \cdot \alpha^{\frac{\alpha}{1-\alpha-\beta}} \cdot \beta^{\frac{\beta}{1-\alpha-\beta}} \cdot b^{-\frac{\alpha+\beta}{1-\alpha-\beta}}+b \cdot M-f(M)$. Thus, the firm's problem is characterized by ${ }^{17}$

$$
\max _{M}(1-\tau) \pi^{*} \text { s.t. } \tau=\gamma \cdot \Phi
$$

Under the formerly derived results, we get the first-order condition $0=(1-\tau) \cdot \frac{\partial \pi^{*}}{\partial M}-\frac{\partial \tau}{\partial M} \cdot \pi^{*}$, which can be simplified to

$$
\frac{\partial\left[(1-\tau) \pi^{*}\right]}{\partial M}=(1-\tau) \cdot(b-c M)-\frac{\partial \tau}{\partial M} \cdot \pi^{*}=0 .
$$

Since $\frac{\partial \tau}{\partial M} \cdot \pi^{*}>0$ and $0<\tau<1$, we see from (19) that $b>c M$. This lies in contrast to the case where the parties bargain over wages only, which means that the firm will choose an amount of outsourcing lower than the level at which the marginal costs of outsourcing equals the marginal cost of domestic labor. Comparing the optimal amount of outsourcing under the different bargaining approaches and the reasonable assumption that $b<w$, we can conclude from the conditions $b>c M$ respectively $w<c M$, that the bargained profit share approach leads to a lower investment in outsourced production.

However, our focus is on the impact of labor market imperfection. As one can see from (12) and (13), the labor union's bargaining power affects the optimal profit share and the impact of outsourcing on the profit share. For a given amount of outsourcing, a stronger labor union reaps a higher share of the profit, which is seen in (12). Since outsourcing increases profits there is an incentive to reduce outsourcing. This effect will be reinforced, if the firm takes into account the impact of outsourcing on the profit share. With higher outsourcing, the firm faces a weaker bargaining position, which decrease the firm's owner earned profit (see equation (13)). However, a more powerful labor union is able to reap a larger share, which

17 According to (12) the profit share mark-up is $\Phi=\frac{\pi^{*}+b M}{\pi^{*}+b M-f(M)}$. 
has also an incentive for less outsourcing. Since both effects lead to the same direction, the firm's owner faces a higher incentive to reduce outsourcing in the presence of a strong labor union in order to reap a higher share of the profit.

\section{Proposition 4: If parties bargain over wage and a profit share, strategic outsourcing will become lower with a higher labor union's bargaining power.}

Thus, the bargaining structure and the power of the labor union are crucial for the amount of outsourcing. The reason for this is that a stronger labor union induces different effects on the firm's cost parameters.

In the case of a bargained profit share, the wage is the exogenous alternative income and is not affected by outsourcing. Thus, the relevant cost parameter for determining the amount of outsourcing in this approach is the distribution parameter, respectively the profit share. Since higher outsourcing decreases the share of profit the firm owner earns, due to a higher loss in case of a disagreement, there is - independent of the power of the union - an incentive for less outsourcing. However, this incentive will be reinforced by a stronger labor union, since the profit share also reflects the bargaining power, which means that a higher union bargaining power decreases the firm's profit share. As a consequence, the firm will react with less outsourcing, if the labor union becomes stronger.

In contrast, if the parties bargain over the wage only, the wage is the cost parameter. With that structure, the firm can realize a higher profit due to by increasing the amount of outsourcing only if the labor union is sufficiently strong, in which case a wage-moderating effect of outsourcing occurs. Therefore, a strong labor union increases the incentive for higher outsourcing, in order to reduce the labor cost.

Following from this argumentation, it is straight-forward to see that the different bargaining structures lead to different amounts of outsourcing for a given union's bargaining power. Thus, we can conclude that bargaining over wages and profit sharing leads to less outsourcing than the classical wage bargaining. 


\section{Conclusions}

The main goal of this paper was to show the effect of outsourcing on workers' income, if the domestic labor market is characterized by a market imperfection, which was modeled as a bargaining between a firm and a labor union. In our analysis we distinguished between two approaches, one where the union and firm negotiate over wages only, and a second, as discussed in the political debate, where the parties bargain over both wage and profit share.

For the first case, it has been found that outsourcing will reduce (increase) workers' income, if the labor union's bargaining power is sufficiently high (low). In contrast, we have found that outsourcing will increase workers income, if the labor union and firm bargain over the wage and a profit share. Thus, the bargaining structure in combination with the union bargaining power is crucial for the income effect. While in a pure wage bargaining the income effects depends on the power of the labor union and therefore the fear of lower income with higher outsourcing can be support under certain circumstances, in a wage and profit share bargaining the fear of lower income can be unambiguously non-certificable.

Concerning the effect of the labor market imperfection on strategic outsourcing, we find different results as well. The reason for this is that outsourcing has different effects on the firm's cost parameter. If the parties bargain over the wage level only, the wage is the cost parameter. Since the impact of outsourcing on the wages depends on the union's bargaining power, this affects the optimal amount of outsourcing. Here we find that due to the wage-moderating (increasing) effect of outsourcing in the presence of a sufficiently strong labor union, outsourcing will become higher (lower) if the labor union's bargaining power is sufficiently high (low).

If the wage and the profit share are determined simultaneously, the wage equals the exogenous alternative income. This means that only the profit share characterizes the firm's cost parameter. Since the profit share is increasing in the

power of the labor union and outsourcing, this provides an incentive for less outsourcing and thus for a higher income of the firm. 
Based on this knowledge, we could compare the optimal amount of outsourcing under the different bargaining approaches. Here we find that for an equal and sufficiently strong labor union, the firm's optimal investment in outsourced products is lower in the case of a simultaneously bargained wage and profit share.

Thus, in order to reduce the fear of substitution and lower income of domestic employment, the union has an incentive to adopt profit sharing as a part of the bargaining and compensation package.

\section{Appendix A: Derivation of the wage effects}

As the mark-up we have $A=\frac{\gamma \cdot \eta[\eta(1-\alpha-\beta)-(\alpha+\beta)]+(1-\gamma)(\alpha+\beta)}{(\eta-1) \gamma \cdot[\eta(1-\alpha-\beta)-(\alpha+\beta)]+(1-\gamma)(\alpha+\beta)}=\frac{T}{Z}$, which depends on the wage $w$ and the amount of outsourcing $M$. The impact of the base wage can be written as $A_{w}=\frac{T_{w} \cdot Z-T \cdot Z_{w}}{Z^{2}}$, where $T_{w}=\gamma \cdot \eta_{w} \cdot((1-\alpha-\beta)+M / L)-\gamma \cdot \eta \frac{M}{L^{2}} L_{w}$ and $Z_{w}=T_{w}+\gamma \cdot \frac{M}{L^{2}} L_{w}$. Using this we have

$$
A_{w}=\frac{\gamma}{Z^{2}}\left[-\eta_{w} \cdot \gamma \cdot\left((1-\alpha-\beta)+\frac{M}{L}\right)^{2}-\frac{M}{L} \frac{\eta}{w}(1-\gamma)(\alpha+\beta)\right] .
$$

Since $\eta_{w}=\frac{1}{1-\alpha-\beta} \frac{\eta}{w} \frac{M}{L}>0$ we have $A_{w}<0$ and thus $1-\frac{A_{w} w}{A}>0$.

We analyze the impact of outsourcing on the mark-up in a similar way. Here we have $A_{M}=\frac{T_{M} \cdot Z-T \cdot Z_{M}}{Z^{2}}$, where $T_{M}=\gamma \cdot \eta_{M} \cdot\left((1-\alpha-\beta)+\frac{M}{L}\right)+\gamma \cdot \eta \frac{L-M \cdot L_{M}}{L^{2}}$ and $Z_{M}=T_{M}-\gamma \cdot \frac{L-M \cdot L_{M}}{L^{2}}$. Using these expressions, we find that

$$
A_{M}=\frac{\gamma}{Z^{2}} \frac{\eta}{L}\left[-\gamma(\eta(1-\alpha-\beta)-(\alpha+\beta))^{2}+(1-\gamma)(\alpha+\beta)(1-\alpha-\beta)\right] .
$$

From (A2) we have 


$$
A_{M}\left\{\begin{array}{l}
< \\
>
\end{array}\right\} \text { as } \gamma\left\{\begin{array}{l}
> \\
= \\
<
\end{array}\right\} \frac{(\alpha+\beta)(1-\alpha-\beta)}{[\eta(1-\alpha-\beta)-(\alpha+\beta)]^{2}+(\alpha+\beta)(1-\alpha-\beta)},
$$

which gives equation (9) by using the wage elasticity (5). QED.

\section{Appendix B: Relationship between profit sharing and outsourcing}

Equation (12) can be written as $\quad \tau=\gamma \cdot \frac{V+b M}{V+b M-f(M)}$, where $V=b^{-\frac{\alpha+\beta}{1-\alpha-\beta}} \cdot \alpha^{\frac{\alpha}{1-\alpha-\beta}} \cdot \beta^{\frac{\beta}{1-\alpha-\beta}}(1-\alpha-\beta)$. Thus, the effect of outsourcing on bargained profit sharing can be written as $\frac{\partial \tau}{\partial M}=\gamma \frac{-f(M) \cdot b+f^{\prime}(M) \cdot V+f^{\prime}(M) \cdot b M}{(V+b M-f(M))^{2}}$. Using $f(M)=\frac{1}{2} c M^{2}$, we can reformulate the effect of outsourcing on profit share to

$$
\frac{\partial \tau}{\partial M}=\gamma \frac{c M\left[V+\frac{1}{2} b M\right]}{(V+b M-f(M))^{2}},
$$

which is equation (13). QED.

\section{References:}

Anderson, S. and M. Devereux (1989): Profit Sharing and Optimal Labor Contracts, Canadian Journal of Economics 89, 425-433.

Bhagwati, J., A. Panagariya and T. N. Srinivasan (2004): The Muddles over Outsourcing, Journal of Economic Perspectives 18, 93-114.

Cable, J. R. and F. R. FitzRoy (1980): Cooperation and Productivity: Some Evidence from West Germany's Experience, Economic Analysis and Workers Management 14, 163-190.

Cahuc, P. and A. Zylberberg (2004): Labor Economics, the MIT Press.

Conyon, M. and R. Freeman (2004): Shared Modes of Compensation and Firm Performance: U.K. Evidence, in Card, D. R. Blundell and R. B. Freeman (eds): Seeking a Premier Economy: the Economic Effects of British Economy Reforms 1980-2000, 109-146. 
Danthine, J.-P. and J. Hunt (1994): Wage Bargaining Structure, Employment and Economic Integration, Economic Journal 104, 528-541.

Estrin, S., Perotin, V., Robinson, A. and N. Wilson (1997): Profit-Sharing in OECD Countries: a Review and Some Evidence, Business Strategy Review 8, 27-32.

Feenstra, R. and G. Hanson (1999): The Impact of Outsourcing and Hightechnology Capital on Wages: estimates for The United States 1979-1990, Quarterly Journal of Economics 114, 907-940.

Freeman, R. B. (1995): Are Your Wages Set in Beijing?, Journal of Economic Perspectives 9, 15-32.

Glass A. J. and K. Saggi (2001): Innovation and Wage Effects of International Outsourcing, European Economic Review 45, 67-85.

Geischecker, I. and H. Görg (2008): Winners and Losers: A Micro-Level Analysis of International Outsourcing and Wages, Canadian Journal of Economics 41, 243-270.

Görg, H. and A. Hanley (2005): Labor Demand Effects of International Outsourcing: Evidence from Plant-Level Data, International Review of Economics and Finance 14, 365-376.

Hasan, R., D. Mitra and R. V. Ramaswamy (2007): Trade Reforms, Labor Regulations, and Labor-Demand Elasticities: Evidence from India, Review of Economics and Statistics 89, 466-481.

Holmlund, B. (1990): Profit Sharing, Wage Bargaining and Unemployment, Economic Inquiry 28, 257-268.

Hummels, D., D. Rapoport and K.-M. Yi (1998): Vertical Specialization and the Changing Nature of World Trade, Economic Policy Review 4, 79-99.

Hummels, D., J. Ishii and K.-M. Yi (2001): The Nature and Growth of Vertical Specialization in World Trade, Journal of International Economics 54, 7596.

Jerger, J. and J. Michaelis (1999): Profit Sharing, Capital Formation and the NAIRU, Scandinavian Journal of Economics 101, 257-275.

Jones, D. C. and J. Pliskin (1991): The Productivity Effects of Profit Sharing and Worker Representation on the Board, Working Paper Hamilton College, No. 91.

Koskela, E. and R. Schöb (2009): Outsourcing of Unionized Firms and the Impact of Labor Market Policy Reforms, forthcoming in: Review of International Economics. 
Koskela, E. and R. Stenbacka (2009): Equilibrium Unemployment with Outsourcing under Labour Market Imperfections, Labour Economics 16, 284290.

Kruse, D. L. (1993): Does Profit Sharing Affect Productivity?, NBER Working Paper, No. 4542.

Lommerud, K. E., F. Meland and O. R. Straume (2009): Can Deunionization Lead to International Outsourcing?, Journal of International Economics 77, 109119.

Naylor, R. (1998): International Trade and Economic Integratio when Labour Markets Are Generally Unionized, European Economic Review 42, 12521267.

Naylor, R. (1999): Union Wage Strategies and International Trade, Economic Journal 109, 102-125.

Pendleton, A., E. Poutsma, J. van Ommeren and C. Brester (2001): Employee Share Ownership and Profit Sharing in the European Union, Office for Official Publications of the European Commission, Luxembourg.

Perry, C. R. (1997): Outsourcing and Union Power, Journal of Labor Research 18, 521-534.

Pohjola, M. (1987): Profit Sharing, Collective Bargaining and Employment, Journal of Institutional and Theoretical Economics 143, 334-342.

Senses, M. Z. (2010): The Effects of Offshoring on the Elasticity of Labor Demand, Journal of International Economics 81, 89-98.

Slaughter, M. (2001): International Trade and Labor-Demand Elasticities, Journal of International Economics 54, 27-56.

Skaksen, M. Y. and J. R. Sorensen (2001): Should Trade Unions Appreciate Foreign Direct Investments, Journal of International Economics 55, 379-390.

Weitzman, M. L. (1987): Steady State Unemployment under Profit Sharing, the Economic Journal 97, 86-105.

Yeats, A. (2001): Just how big is Global Production Sharing?, in S. W. Arndt and H. Kierzkowski (eds.): Fragmentation: New Production Patterns in the World Economy, Oxford University Press, New York, 108-143. 